\title{
Deformation in the lower crust and downward extent of the San Andreas Fault as revealed by teleseismic waveforms
}

\author{
Lupei Zhu \\ Department of Earth and Atmospheric Sciences, Saint Louis University, St. Louis, Missouri 63103, U.S.A.
}

(Received January 14, 2002; Revised August 5, 2002; Accepted August 9, 2002)

\begin{abstract}
High resolution images of crustal structure across the San Andreas Fault (SAF) were obtained by using the common conversion point stacking of teleseismic $P$-to- $S$ converted waves recorded during the Los Angeles Region Seismic Experiments (LARSE-I and II). In the upper crust, several sedimentary basins were delineated in the images, including the San Fernando and the Santa Clarita Basins. The San Fernando Basin reaches a depth of $8 \mathrm{~km}$ under the northern edge of the San Fernando Valley. On the LARSE-I profile, the downward projection of the SAF truncates several lower crustal interfaces including the Moho on both sides. The Moho is vertically offset by as much as $8 \mathrm{~km}$. Along the LARSE-II profile, the impedance contrast and slope of the Moho are seen to change across the fault. These results indicate that the fault penetrates into the lower crust and probably uppermost mantle as a narrow $(<10 \mathrm{~km})$ feature. The Moho beneath the San Gabriel Mountains is shallower $(\sim 26 \mathrm{~km})$ than under the San Gabriel Valley to the south and the Mojave Desert to the north, suggesting that the mountain ranges were lifted en masse by horizontal compression. On the northeast side of the SAF, the Mojave Desert has a sharp and essentially flat Moho at a depth of $\sim 32 \mathrm{~km}$. The lower crustal structure beneath the San Fernando and Santa Clarita Valleys along the LARSE-II profile south of the SAF is complicated as indicated by the large undulation and low impedance contrast of the Moho. These observations suggest that the deformation in the lower crust is localized and often concentrates near boundaries of crustal blocks or beneath those places which have experienced intensive faulting and deformation in the upper crust.
\end{abstract}

\section{Introduction}

It is widely accepted that the continental crust can be divided into a brittle upper crust whose strength is determined by the friction law and a lower crust which is relatively weak and where deformation takes place in the form of ductile flow (e.g. Molnar, 1992). This view is supported by the lack of earthquakes in the lower crust in most places. However, the transition from brittle to ductile deformation and the coupling of the two zones are not clear. The upper crust is broken into blocks of different sizes by faults. Do these faults extend into the lower crust or become a broad shear zone at depth? Is the motion of crustal block across the fault driven by forces applied on edges of the region or by basal traction at the bottom of the upper crust? Answers to these questions have important implications for relating surface observations to deep processes and understanding continent dynamics.

One way to address this problem is to study deformation in the lower crust. For example, the lack of Moho offset and topography in the Basin and Range Province led to the conclusion that the normal faulting there is accommodated in the upper crust and decoupled from the lower crust (Froidevaux, 1986; Zuber et al., 1986). There are other places where large vertical strike slip faults seem to penetrate into the uppermost mantle (e.g. McBride and Brown, 1986; Lemiszki and Brown, 1988; Holbrook et al., 1996; Henstock et al., 1997;

Copy right (C) The Society of Geomagnetism and Earth, Planetary and Space Sciences (SGEPSS); The Seismological Society of Japan; The Volcanological Society of Japan; The Geodetic Society of Japan; The Japanese Society for Planetary Sciences.
Stern and McBride, 1998). Most of these observations come from seismic surveys using active sources and vertical reflection and refraction techniques. Although these high frequency signals can provide high resolution, they suffer from influences of small scale heterogeneities and insufficient signal penetration depth. As a consequence, interpreting active source seismic profiles can be highly non-unique and controversial.

In recent years, a new technique has been developed which uses teleseismic $P$-to- $S$ converted waves to image crustal and upper mantle structures (Dueker and Sheehan, 1997; Shen et al., 1998; Li et al., 1998; Jones and Phinney, 1998; Kosarev et al., 1999; Zhu, 2000). Compared with active source techniques, it has several advantages: 1) structures are illuminated by waves from below, thus the penetration depth is not limited; 2) signals are strong and have an intermediate frequency range $(\sim 1 \mathrm{~Hz})$. They are not sensitive to small scale (sub-kilometer) heterogeneities and still have high enough spatial resolution (a few kms) to detect important structural variations; 3 ) rays have steep incident angles, which gives the technique good lateral resolution capability; 4) the primary $P$-to- $S$ converted waves travel only one way from target to receiver and are therefore less contaminated by shallow heterogeneous structures; 5) the technique uses travel time differences between the direct $P$ wave and later $P$-to- $S$ converted waves. This greatly reduces the trade-off between structures and crustal velocities.

In this report, I present two images of crustal structure 
across the San Andreas Fault (SAF) in southern California derived from teleseismic waveforms. I first give a brief description of the data and the imaging procedure, followed by the results. I will use these results to infer deformation in the lower crust and the downward extent of the SAF.

\section{Data}

The teleseismic waveform data used in this study were mostly collected during the Los Angeles Region Seismic Experiment (LARSE) (Fuis et al., 2001a). LARSE is largely an active source imaging experiment with a small component of passive recording. In 1994 the first profile was completed from the southern foothill of the San Gabriel Mts to the Mojave Desert (Fig. 1). A second profile in 1999 started near the coast in Malibu and traversed the San Fernando and Santa Clarita Valleys, the Western San Gabriel Mts, ending in the Antelope Valley of the Mojave Desert. Both profiles were occupied by a linear array of three-component seismometers to record earthquakes before the active experiment. In the first profile, only 89 short-period instruments were used and the recording lasted for one month. Even so, 30 teleseismic events were well recorded by the array, producing 1500 three-component records. The second passive recording experiment lasted for 6 months with a mix of 37 broadband instruments and 46 short-period ones. I was able to use 4527 three-component waveform records from 92 teleseismic events. Both data sets were augmented by permanent digital seismic stations located near the two profiles (see Fig. 1).

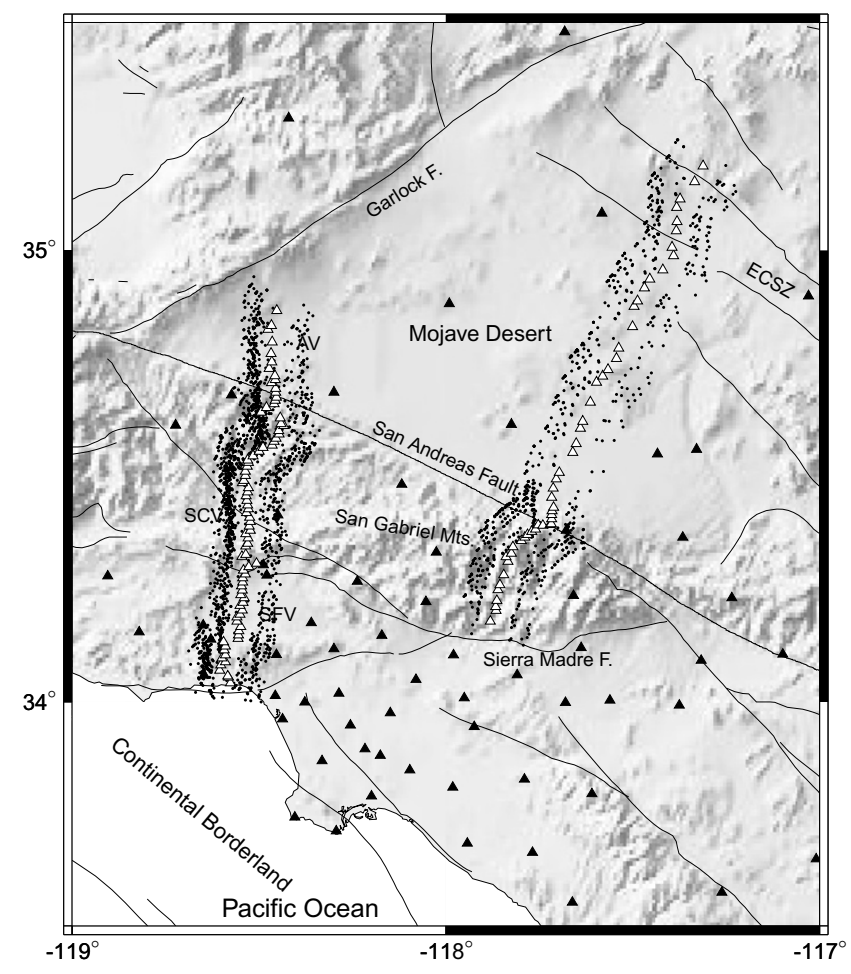

Fig. 1. Locations of the three-component stations (open triangles) in the LARSE-I (right) and LARSE-II (left) passive recording experiments. Dots are the $P$-to- $S$ conversion points at the Moho of teleseismic receiver functions. Solid triangles are permanent broadband digital stations. AV Antelope Valley; ECSZ: Eastern California Shear Zone; SCV: Santa Clarita Valley; SFV: San Fernando Valley.
The initial data processing consisted of the following steps: 1) $P$ waveforms were retrieved $50 \mathrm{~s}$ before the direct $P$ arrival and $100 \mathrm{~s}$ after it; 2) All records from each teleseismic event were aligned on the first $P$ arrival using crosscorrelation. I then stacked all aligned vertical components to obtain the effective source time function for this event. The effective source time function represents the waveform shape before it interacts with crustal structure under each station; 3) The effective source time function was removed from all three-component waveforms using a time-domain deconvolution technique (Taylor and Toksoz, 1982). The outputs are teleseismic receiver functions which can be treated as the impulse response of crustal structure under each station for a near vertically incident $P$ plane wave. In addition to the direct $P$ arrival, the radial component of receiver function contains mainly $P$-to- $S$ converted waves generated from various crustal velocity interfaces. They will be used in the next stage to create structural images along the LARSE lines.

\section{Method}

To image crustal structure using receiver functions, I developed a Common Conversion Point (CCP) stacking technique (Zhu, 2000). This technique uses the ideas of Common Middle Point (CMP) stacking and migration in reflection seismology. But instead of dealing with reflected waves, it is applied to converted waves. First, I migrate the timedomain receiver functions into the depth domain. I assume that every amplitude on the radial receiver function is produced by a primary $P$-to- $S$ conversion at some depth. The depth is determined by the time delay of the amplitude with respect to the direct $P$ using a background velocity model. The amplitude itself is proportional to the velocity, or more precisely the impedance contrast at that location. After the migration, the crustal volume is divided into bins of designated size and all amplitudes in the same bin are stacked to produce a structural image. The image delineates various interfaces in the crust as well as the Moho which is usually the largest discontinuity.

Some of the energy in the radial receiver functions are produced by multiple $P$-to- $S$ conversions which will be mapped to deeper locations by the migration. But multiples tend to be less coherent than the primary conversion because of their extra reflections at the surface and longer paths in the heterogeneous shallow crust. They also have different kinematics from the primary converted phase so that multiples generated from the same interface but with different incident angles will be mapped to different depths. When stacking many receiver functions from different events and receivers, multiples and noise are suppressed and the primary conversions are enhanced. Therefore, a key to the success of CCP stacking is having an array of densely distributed stations and a good azimuthal distribution of earthquakes. Typically the $P$ to- $S$ conversion point at the bottom of a $30 \mathrm{~km}$ thick crust is about $7 \mathrm{~km}$ horizontally away from the station. To insure that the rays overlap and criss-cross, the station spacing should be less than half that distance. For the LARSE experiments, the station spacing is less than $2 \mathrm{~km}$.

The migration uses a background velocity model to compute ray paths and travel times, thus there is a trade-off between the depths of discontinuities and the crustal velocities. 
However, since the direct $P$ arrival time is used as the reference time for converted waves, the results are not sensitive to crustal $P$-wave velocity. They are, however, very sensitive to the crustal $V_{p} / V_{s}$ ratio. It was shown that the change of the Moho depth is less than $1 \mathrm{~km}$ for $4 \%$ change in $V_{p}$ of the whole crust, but the same percentage of change in the crustal $V_{p} / V_{s}$ ratios can change the Moho depth by as much as $3 \mathrm{~km}$ (Zhu and Kanamori, 2000). Crustal $V_{p} / V_{s}$ ratio can be obtained from regional $P$ and $S$-velocity tomographic models or estimated using multiple $P$-to- $S$ conversions in receiver functions of broadband stations (Zhu and Kanamori, 2000).

The station locations and the $P$-to- $S$ conversion points of teleseismic rays at a depth of $30 \mathrm{~km}$ are shown in Fig. 1. We can see that along each profile a crustal volume of $\sim 30 \mathrm{~km}$ wide centered at the profile is well sampled by these rays. Consequently, two dimensional (2-D) images were generated using the CCP technique to reveal crustal structure variation along the two profiles. Because of the linear array configuration of the experiments and the limited number of earthquakes, I did not try resolve the structural variations perpendicular to the profiles. On the other hand, since both profiles are orthogonal to the surface geological trend (Fig. 1), such variations within the width of the profiles are expected to be minor.

I used the three-dimensional (3-D) $P$ and $S$-velocity models of Hauksson (2000) as the background velocity models for migration. These tomographic velocity models were determined on $15 \mathrm{~km}$ spacing horizontal grids using $P$ and $S-P$ travel times from local earthquakes and controlled sources. They are well resolved down to a depth of $22 \mathrm{~km}$ in our study area. Shallow crustal structures such as major sedimentary basins are clearly depicted in the models. The crustal velocities below $22 \mathrm{~km}$ were fixed using a modified Hadley and Kanamori (1977) southern California velocity model with a transitional Moho between 31 and $33 \mathrm{~km}$. The CCP stacking needs to track $S$-to- $P$ conversions along each ray path and their differential travel times with respect to the direction $P$, which is too complex for a possible full 3-D ray tracing program. I used a simplified approximation approach to take the advantage of efficiency of 1-D ray tracing: for each station, the migration was done using the local 1 -D velocity model (the vertical slice in the 3 -D model at the station location). The 3-D feature of the background velocity is accounted for by different 1-D velocity models at different stations. The approach is justified by the fact that teleseismic rays travel in the crust nearly vertically and are only sensitive to velocity structure within $10 \mathrm{~km}$ of lateral extent under the station.

For stacking, I used a bin size of $1 \mathrm{~km}$ along the profile and a $0.5 \mathrm{~km}$ in depth. Amplitudes of receiver function, corrected for different incidence angle, are assigned to bins sampled by the ray path. An improvement I made over the CCP stacking technique of Zhu (2000) is that rays are not treated as having infinite small width. The width of the ray is calculated using its Fresnel zone size, $\sqrt{\lambda z}$ where $\lambda$ is its wavelength and $z$ is depth. At a $30 \mathrm{~km}$ depth this width is $\sim 10 \mathrm{~km}$ while near the surface it is 1 to $2 \mathrm{~km}$. Finite ray widths increase model sampling and produce a smooth stacked image. The smoothing distance varies adaptively according to the size of the Fresnel zone.

\section{Results}

\subsection{LARSE-I profile}

A total of 972 receiver functions are obtained using the LARSE-I data set. An additional 637 receiver functions are computed using 5 permanent broadband stations near the profile. A 2-D CCP crustal image along this profile was presented in Zhu (2000) where detailed discussions can be found. Figure 2 shows the image using the improved CCP stacking technique described above. Red represents positive $P$-to- $S$ converted amplitudes and normally indicates sharp increase in the impedance with depth. The Moho discontinuity under the Mojave Desert is clearly visible as a continuous, nearly flat feature at a $32 \mathrm{~km}$ depth. Its depth increases gradually from $30 \mathrm{~km}$ in central Mojave to $35 \mathrm{~km}$ toward the SAF where it is truncated right below the surface trace of the fault. South of the SAF there are several bands of large converted amplitudes with depth ranging from $10 \mathrm{~km}$ to $40 \mathrm{~km}$. The most likely Moho is the one near $28 \mathrm{~km}$ because it is the most continuous and its depth agrees with the estimated Moho depth of Zhu and Kanamori (2000) under a broadband station (CPP) in the area. It too terminates at the downward extension of the SAF.

The CCP image was compared with the results from the LARSE-I seismic reflection and refraction data (Ryberg and Fuis, 1998; Lutter et al., 1999; Fuis et al., 2001b). The mid-crustal interfaces at depths of 13 and $18 \mathrm{~km}$ in the CCP image (labeled as A and B) beneath the San Gabriel Mts are apparent as "bright zones" in the vertical reflection profile (Ryberg and Fuis, 1998). The southward dipping Moho north of the SAF and the Moho at $28 \mathrm{~km}$ beneath the northern San Gabriel Valley are in good agreement with the reflection results of Ryberg and Fuis (1998) and Fuis et al. (2001b). A discrepancy exists on the location of Moho beneath the San Gabriel Mts between the CCP result and the synthesis model by Fuis et al. (2001b) based on the LARSE-I active source results. In their model a northward dipping Moho is drawn to connect the Moho beneath the northern San Gabriel Valley to the deeper Moho under the SAF, forming a crustal root under the mountain ranges. A similar crustal root model was suggested by Kohler and Davis (1997) from inverting teleseismic travel time residuals recorded by the LARSE-I stations. The CCP image, however, shows that the Moho becomes shallow $(26 \mathrm{~km})$ under the San Gabriel Mts and there is a Moho offset of $\sim 8 \mathrm{~km}$ directly beneath the SAF. A modeling of the Bouguer gravity anomaly along the LARSEI profile favors the shallow Moho over the crustal root model (Zhu, 2000). It is noted that reflectivity from the lower crust in the San Gabriel Mts portion of the LARSE-I profile is very complicated and no firm Moho reflector was identified at the expected depth of the crustal root. Determining crustal thickness using teleseismic travel times is notoriously nonunique and suffers from the trade-off between thickness and crustal velocities.

\subsection{LARSE-II profile}

Data quantity and quality were improved greatly in the LARSE-II passive recording experiment, partly due to its longer duration and inclusion of broadband seismic instruments. On the other hand, the profile traverses two large, densely populated sedimentary basins, the San Fernando and the Santa Clarita Basins, which caused culture noises and 

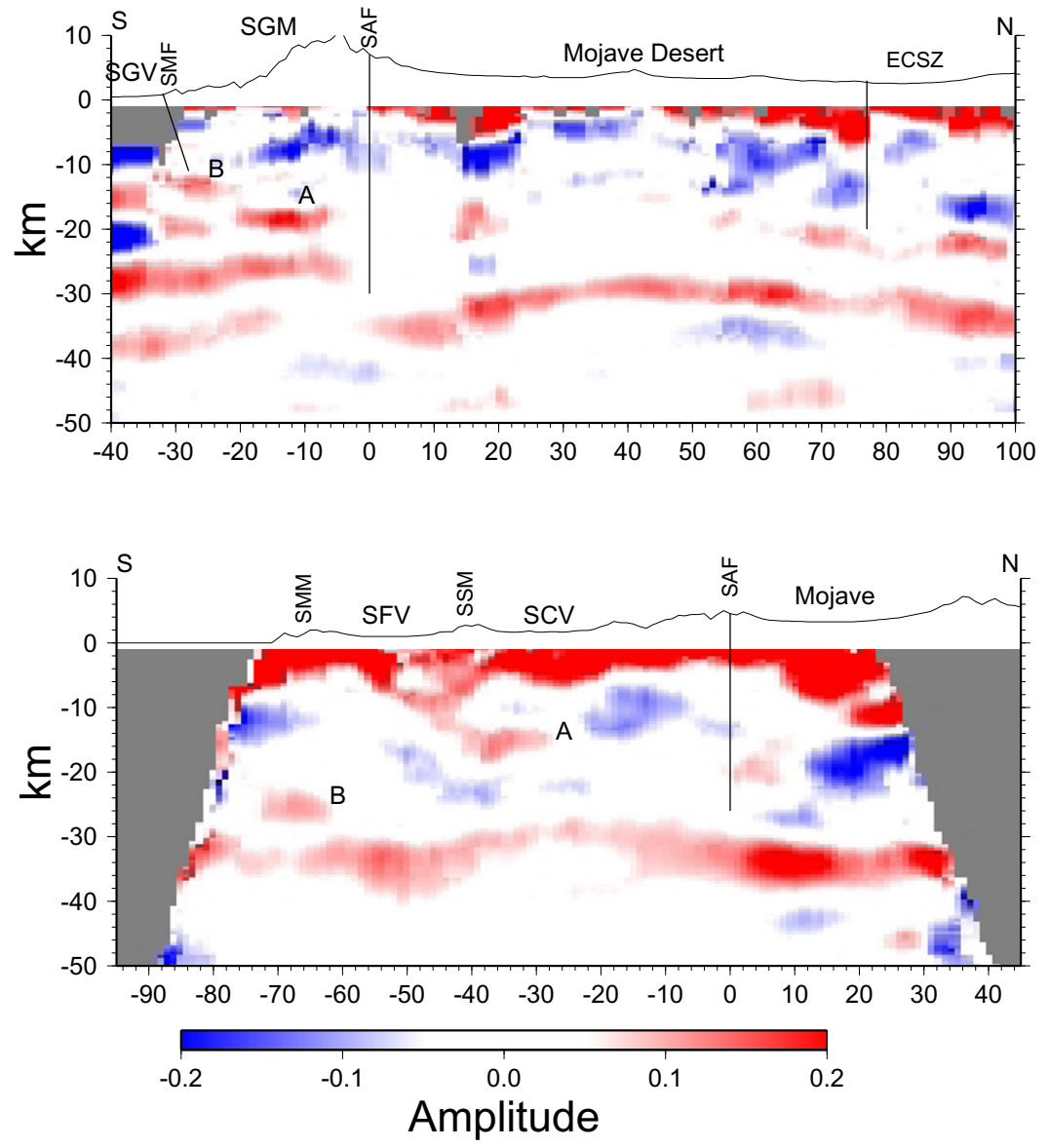

Fig. 2. CCP stacking images along the LARSE-I (top) and LARSE-II (bottom) profiles. Red represents positive $P$-to- $S$ converted amplitudes and normally indicates sharp increase in the impedance with depth. The strong positive amplitudes near the surface are produced by the large impedance contrast from sediments to basement rocks. There is no vertical exaggeration except that the surface topography is amplified by a factor of 2. SAF: San Andreas Fault; SGM: San Gabriel Mts; SGV: San Gabriel Valley; SMF: Sierra Madre Fault; SMM: Santa Monica Mts; SSM: Santa Susana Mts.

site-related waveform complexity in the records. I stacked 1940 receiver functions from the temporary stations and 799 receiver functions from 9 nearby permanent stations to form the CCP image (Fig. 2). In the upper crust portion of the image the bottoms of the San Fernando and Santa Clarita Basins are delineated. In the image the San Fernando Basin extends to $\sim 8 \mathrm{~km}$ below sea level and the deepest part lies under the northern edge of the San Fernando Valley. The Santa Clarita Basin is shallower with a maximum depth of $\sim 4 \mathrm{~km}$. In addition to these two sedimentary basins, the image shows that the Antelope Valley in the Mojave Desert is also underlaid by a low velocity body to a depth of $5 \mathrm{~km}$ which could be another sedimentary basin or basement rocks with low seismic velocities. The mid-crust is essentially free of $P$-to- $S$ conversions except beneath the Santa Susana Mts and southern Santa Clarita Valley where a short horizon exists at a depth of $15 \mathrm{~km}$ (labeled as A). In the lower crust a strong and flat Moho can be seen under the Mojave Desert at a depth of $\sim 34 \mathrm{~km}$, similar to the LARSE-I profile. Unlike the LARSE-I, the Moho can be traced southward across the downward projection of the SAF but with reduced amplitude. The projection point also marks a change of Moho attitude from flat in the Mojave Desert to a ramp south of the SAF. The Moho rises to as shallow as $29 \mathrm{~km}$ beneath the Santa Clarita Valley before it deepens again to $34 \mathrm{~km}$ beneath the San Fernando Valley. South of the San Fernando Valley beneath the Santa Monica Mts another $P$-to- $S$ conversion horizon (B) appears at a depth of $25 \mathrm{~km}$ above the continuation of the $34 \mathrm{~km}$ deep Moho. It was estimated that offshore Continental Borderland has a crustal thickness of $\sim 22 \mathrm{~km}$ (Zhu and Kanamori, 2000; Hauksson, 2000). Therefore, the $25 \mathrm{~km}$ conversion might be from the Moho of offshore crust. In such a case, the transition of crust from the offshore Continental Borderland to the onshore western Transverse Ranges occurs rapidly under the Santa Monica Mts in a form of Moho step or double Mohos.

I compared the above results with the LARSE-II active source experiment results. Lutter et al. (2001) used refraction and reflection data to determine upper crustal structure along the profile. They reported asymmetric basins beneath both San Fernando and Santa Clarita Valleys. The basinbottom reflections and iso-velocity lines under the San Fernando Valley dip gently northward from the Santa Monica Mts to 5-6 km below sea level in the northern part of the valley. Similar reflections and iso-velocity lines dip southward from the north margin of the Santa Clarita Valley to $3.5-4.5 \mathrm{~km}$ in the central part of the valley. In addition, a low velocity patch was imaged beneath the Antelope Valley. These results are consistent with the CCP image except that the San Fernando Basin is $\sim 2 \mathrm{~km}$ deeper in the CCP image. 
Reflectivity from the lower crust along the LARSE-II profile is very complicated. No Moho reflection has been reported yet. Fuis et al. (2001c) reported a broad north-dipping zone $\left(25-35^{\circ}\right)$ of reflectivity from below the Santa Clarita Valley to the base of crust which intersects a broad south-dipping zone of reflectivity from the Mojave Desert approximately beneath the surface trace of the SAF. Such feature is not present in the CCP image.

\section{Discussions and Conclusions}

Application of the CCP stacking technique to the LARSE teleseismic waveform data demonstrated that it is an effective technique for subsurface imaging. Both shallow (e.g. basin shapes) and deep crustal structures (e.g. Moho topography) can be delineated. The imaging technique is complementary to seismic tomography because it reveals structural variation while the latter is more sensitive to velocity variation. It uses teleseismic waveform data from passive recording experiment whose cost is usually a small fraction of that of a similar active source experiment. Its resolution power is comparable to those of active source techniques for the upper crust but seems superior for the middle and lower crust depth range.

The CCP images along the two LARSE profiles shed new light on the deep extent of the SAF. On the LARSE-I profile, the downward projection of the fault truncates several lower crustal interfaces including Moho on both sides. Along the LARSE-II profile, the impedance contrast and slope of the Moho are seen to change across the SAF (Fig. 2). These indicate that the SAF penetrates deep into the lower crust and possibly uppermost mantle as a narrow $(<10 \mathrm{~km})$ feature. This differs from some previous claims that the fault is terminated in the middle crust by a low angle detachment (e.g. Yeats, 1981; Namson and Davis, 1988) or becomes a broad zone of deformation in the lower crust (e.g. Prescott, 1981; Bourne et al., 1998). Whether this feature applies to the entire SAF is not clear. There are reports of crust penetrating SAF in northern and central California using seismic reflection and refraction data (McBride and Brown, 1986; Holbrook et al., 1996; Henstock et al., 1997; Parsons, 1998). But there are also studies in the same region showing that the SAF is terminated by a detachment fault (Furlong et al., 1989; Brocher et al., 1994). Such discrepancy underscores the difficulties of processing and interpreting seismic explosion data for deep crustal structures. Stern and McBride (1998) reviewed seismic work on many continental transform strike-slip faults and concluded that they penetrate all or most of the crust. In this study, because of the advantages of the technique discussed in the method section, the images are more robust and conclusive.

The deformation in the lower crust revealed by the images is by no means continuous and smooth. Deformation is concentrated in places where there are large scale faulting (e.g. SAF) and shearing (e.g. ECSZ) in the upper crust. For crustal blocks such as the Mojave Desert which have been stable over a long geological time without much internal deformation, the lower crust seems intact and the Moho is sharp and flat. In other provinces such as the Transverse Ranges and San Fernando Basin that have experienced intensive compression and extension, the Moho is deformed in a com- plicated way. The Moho upwarp beneath the San Gabriel Mts indicates that the mountain ranges were lifted en masse as a result of crustal buckling under horizontal compression (Zhu, 2000). Large and rapid Moho undulation south of the SAF along the LARSE-II profile is accompanied in the upper crust by interweaving of sedimentary basins and mountain ranges. All these suggest that crustal blocks are not limited to the upper crust and the upper and lower crusts are coupled strongly enough for them to be deformed coherently.

Acknowledgments. Thanks to Tom Brocher, Anne Sheehan, Bob Herrmann, and Editor Greg Beroza for their constructive reviews which greatly improved the manuscript. I am also grateful to $\mathrm{M}$. Kohler and the staff at the IRIS DMC who helped to retrieve the LARSE waveform data. This research was supported by USGS NEHRP grant 00HQGR0007 and NSF grant EAR-0001016.

\section{References}

Bourne, S., P. England, and B. Parsons, The motion of crustal blocks driven by flow of the lower lithosphere and implications for slip rates of continental strike-slip faults, Nature, 391(6668), 655-659, 1998.

Brocher, T., J. McCarthy, P. Hart, W. Holbrook, K. Furlong, T. McEvilly, J. Hole, and S. Klemperer, Seismic evidence for a lower crustal detachment beneath San Francisco Bay, California, Science, 265(5177), 14361439, 1994.

Dueker, K. and A. Sheehan, Mantle discontinuity structure from midpoint stacks of converted $\mathrm{P}$ to $\mathrm{S}$ waves across the Yellowstone hotspot track, $J$. Geophys. Res., 102(B4), 8313-8327, 1997.

Froidevaux, C., Basin and Range large-scale tectonics: constraints from gravity and reflection seismology, J. Geophys. Res., 91, 3625-3632, 1986.

Fuis, G. S., T. Ryberg, N. J. Godfrey, D. A. Okaya, and J. M. Murphy, Crustal structure and tectonics from the Los Angeles basin to the Mojave Desert, southern California, Geology, 29, 15-18, 2001a.

Fuis, G. S., T. Ryberg, N. J. Godfrey, D. A. Okaya, and J. M. Murphy, Crustal structure and tectonics from the Los Angeles basin to the Mojave Desert, southern California, Geology, 29, 15-18, 2001b.

Fuis, G. S., T. Ryberg, W. J. Lutter, E. Hauksson, K. B. Richards-Dinger, T. G. Hildenbrand, V. E. Langenheim, J. M. Murphy, and D. A. Okaya, Deep structure in the region of the San Fernando and Santa Clarita Valleys, southern California, from LARSE II seismic imaging, earthquake relocation, and magnetic modeling - a progress report, Eos. Trans. AGU, 82(47), Fall Meet. Suppl., Abstract S12E-05, 2001c.

Furlong, K., W. Hugo, and G. Zandt, Geometry and evolution of the San Andreas Fault Zone in northern California, J. Geophys. Res., 94(B3), 3100-3110, 1989.

Hadley, D. and H. Kanamori, Seismic structure of the Transverse Ranges, California, Geol. Soc. Am. Bull., 88, 1469-1478, 1977.

Hauksson, E., Crustal structure and seismicity distribution adjacent to the Pacific and North America plate boundary in southern California, $J$. Geophys. Res., 105, 13875-13903, 2000.

Henstock, T., A. Levander, and J. Hole, Deformation in the lower crust of the San Andreas Fault System in northern California, Science, 278(5338), 650-653, 1997.

Holbrook, W., T. Brocher, U. TenBrink, and J. Hole, Crustal structure of a transform plate boundary: San Francisco Bay and the central California continental margin, J. Geophys. Res., 101(B10), 22311-22334, 1996.

Jones, C. H. and R. A. Phinney, Seismic structure of the lithosphere from teleseismic converted arrivals observed at small arrays in the southern Sierra-Nevada and vicinity, California, J. Geophys. Res., 103, 1006510090, 1998.

Kohler, M. D. and P. M. Davis, Crustal thickness variations in southern California from Los Angeles Region Seismic Experiment passive phase teleseismic travel times, Bull. Seismol. Soc. Am., 87, 1330-1344, 1997.

Kosarev, G., R. Kind, S. Sobolev, X. Yuan, W. Hanka, and S. Oreshin, Seismic evidence for a detached Indian lithospheric mantle beneath Tibet, Science, 283(5406), 1306-1309, 1999.

Lemiszki, P. and L. Brown, Variable crustal structure of strike-slip fault zones as observed on deep seismic-reflection profiles, Geol. Soc. Am. Bull., 100(5), 665-676, 1988.

Li, A., K. Fischer, M. Wysession, and T. Clarke, Mantle discontinuities and temperature under the North American continental keel, Nature, 
395(6698), 160-163, 1998

Lutter, W. J., G. S. Fuis, C. H. Thurber, and J. M. Murphy, Tomographic images of the upper crust from the Los Angeles basin to the Mojave Desert, California: Results from the Los Angeles Region Seismic Experiment, $J$ Geophys. Res., 104, 25543-25565, 1999.

Lutter, W. J., T. Ryberg, G. S. Fuis, J. M. Murphy, and D. A. Okaya, Basin structure of the San Fernando and Santa Clarita Valleys and geometry of the Northridge and San Fernando faults as determined from Los Angeles Region Seismic Experiment, Phase II (LARSE II), Eos. Trans. AGU, 82(47), Fall Meet. Suppl., Abstract S11A-0540, 2001.

McBride, J. and L. Brown, Reanalysis of the COCORP deep seismic reflection profile across the San Andreas Fault, Parkfield, California, Bull. Seismol. Soc. Am., 76(6), 1668-1686, 1986.

Molnar, P., Brace-Goetze strength profiles, the partitioning of strike-slip thrust faulting at zones of oblique convergence, and the stress-heat flow paradox of the San Andreas Fault, in Fault Mechanics and Transport Properties of Rocks, edited by B. Evans and T.-F. Wong, Academic Press Ltd., 1992.

Namson, J. and T. Davis, Structural transect of the western Transverse Ranges, California - implications for lithospheric kinematics and seismic risk evaluation, Geol., 16(8), 675-679, 1988.

Parsons, T., Seismic-reflection evidence that the Hayward fault extends into the lower crust of the San Francisco Bay Area, California, Bull. Seismol. Soc. Am., 88, 1212-1223, 1998.

Prescott, W. H., The accommodation of relative motion at depth on the San Andreas Fault System in California, J. Geophys. Res., 86, 999-1004,
1981.

Ryberg, T. and G. Fuis, The San Gabriel Mountains bright reflective zone: possible evidence of young mid-crustal thrust faulting in southern California, Tectonophys., 286(1-4), 31-46, 1998.

Shen, Y., S. Solomon, I. Bjarnason, and C. Wolfe, Seismic evidence for a lower-mantle origin of the Iceland plume, Nature, 395(6697), 62-65, 1998.

Stern, T. and J. McBride, Seismic exploration of continental strike-slip zones, Tectonophys., 286(1-4), 63-78, 1998.

Taylor, S. and M. N. Toksoz, Measurement of interstation phase and group velocities and Q using Weiner filtering, Bull. Seismol. Soc. Am., 72, 7391, 1982.

Yeats, R. S., Quaternary flake tectonics of the California Transverse Ranges, Geol., 9, 16-20, 1981.

Zhu, L., Crustal structure across the San Andreas Fault, southern California from teleseismic converted waves, Earth Planet. Sci. Lett., 179, 183-190, 2000 .

Zhu, L. and H. Kanamori, Moho depth variation in southern California from teleseismic receiver functions, J. Geophys. Res., 105, 2969-2980, 2000.

Zuber, M., E. Parmentier, and R. C. Fletcher, Extension of continental lithosphere: a model for two scales of Basin and Range deformation, J. Geophys. Res., 91, 4826-4838, 1986.

L. Zhu (e-mail: lupei@eas.slu.edu) 